\title{
Research on the Model of Scientific Research Organizations in Guangdong Universities Based on the Perspective of Collaborative Innovation
}

\author{
Li-Na XUAN ${ }^{1, a}$ and Mao-Bing $\mathrm{HE}^{2, \mathrm{~b},{ }^{*}}$ \\ ${ }^{1}$ Guangzhou College of Commerce, Guangzhou, China \\ ${ }^{2}$ South China Normal University, Guangzhou, China \\ axuanlina6@163.com, bhemby2006@qq.com \\ ${ }^{*}$ Corresponding author
}

Keywords: colleges and universities, scientific research organization, collaborative innovation, development.

\begin{abstract}
With the rapid development of Guangdong's social and economic construction, colleges and universities have become the main object of Guangdong's scientific and technological innovation. The rationality of its scientific research organization and its high efficiency have played an important role in the scientific and technological innovation activities of universities. Therefore, an in-depth analysis of the development of scientific research organization models in Guangdong universities an existing problems, the creation of collaborative innovation research organization mode and operational mechanism will help universities break through the shackles of traditional scientific research management models, deepen the reform of scientific research mechanism, establish a synergy mechanism for scientific and technological innovation, and enhance The use efficiency of scientific research resources has important practical significance for colleges and universities to promote the economic development of Guangdong.
\end{abstract}

\section{Introduction}

Guangdong is not only the frontier of China's reform and opening up, but also an important technological innovation base in China. When attending the deliberation of the Guangdong delegation of the 13th National People's Congress, General Secretary Xi Jinping emphasized that Guangdong is the vanguard, pioneering and experimental area of reform and opening up, and has a very important position in the overall situation of China's reform, opening up, and socialist modernization effect. Guangdong should comprehensively promote the reform and innovation of the mechanism system, improve the efficiency of resource allocation efficiency, promote the free flow and aggregation of innovation elements, and make innovation a powerful kinetic energy for high-quality development. In recent years, the relevant departments of the Guangdong Provincial Government have intensified reforms, focused on breaking the institutional and institutional barriers to high-level university construction, continuously expanding and implementing the autonomy of colleges and universities, and promulgating a series of innovative and targeted highlevel university construction support. Measures.

Since 2016, the scientific research strength of Guangdong universities has shown a good momentum of progress. The investment in scientific research in universities reached 16.539 
billion yuan, an increase of 5.004 billion yuan compared with 2015. The total number of teaching and research personnel in colleges and universities in the province was 115,859, and the number of talent reserves increased. There were 24,445 patents, an increase of $24.14 \%$ over 2015; a technology transfer contract was signed. 378 items, the contract amount was 271.356 million yuan, an increase of 68.617 million yuan over 2015, an increase of 33.92\%; the actual income of the year was 1,603,500 yuan, an increase of 52.159 million yuan over 2015, an increase of 48.43\%. According to the "China Regional Innovation Capability Evaluation Report 2017", in 2017, Guangdong's innovation ability ranking ranked first in the country, and innovation input and output capacity led the country. Among them, rich educational resources, especially the development of higher education, is one of the leading innovation factors for Guangdong's innovation ability. In 2018, the number of projects awarded by the National Natural Science Foundation of Guangdong Province was greatly improved, and the total number of projects approved was ranked fourth in the province. Among them, Sun Yat-Sen University has a total of 872 projects, ranking second in the country; 289 universities in Shenzhen, 250 in Southern Medical University, 238 in South China University of Technology, 235 in Jinan University, 136 in Guangzhou University, and 136 in Southern University of Science and Technology, Foshan 40 science and technology colleges, 25 from Dongguan Institute of Technology. It can be seen that the scientific research strength and innovation ability of Guangdong universities have been continuously improved, and the service for Guangdong's innovation-driven development has achieved remarkable results.

At present, the pattern of scientific and technological innovation has gradually evolved from a traditional linear organizational model to an open, cooperative model across regions, transnationals, and organizations. Collaborative innovation has become an extension and deepening of university participation in industry-university-research cooperation, and has become a technological competitiveness. An important way to integrate national strength. How to further promote the development of science and technology innovation capability in Guangdong universities and explore the collaborative innovation research organization model of colleges and universities is particularly important.

\section{Analysis of the Status Quo of the Development of Scientific Research Organization Mode in Guangdong Universities}

In 1985, the "Decision on the Reform of the Education System" emphasized that universities should continuously enhance their research capabilities, scientific research is increasingly valued, and the research organization model is constantly changing.

\section{Vertical scientific research organization model of linear functional system}

From the point of view of the administrative affiliation of the university, the traditional universities are mostly the organizational structure of the university-college (college)-faculty (study) type of linear function system, and the three-level management mode is implemented fig. 1 shows [1]. 


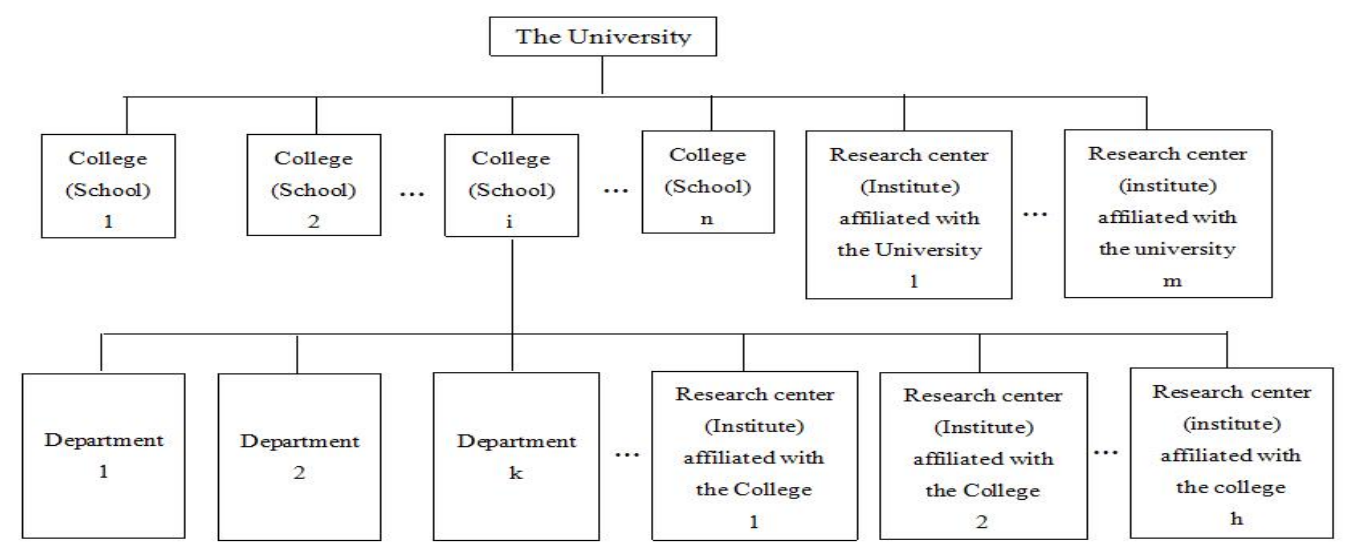

Figure 1. Traditional university academic organization structure based on administrative affiliation

This organizational structure is characterized by the "University-College (School)-Department (Institute)" line management, which implements the unified command of the school and the functional department to assist in the guidance. The department (institute) accepts the school at the same time. Leadership and management of the College (School), as well as business direction and supervision of the functional department. It is characterized by a hierarchical nature, emphasizing that management information is transmitted from top to bottom along a fixed channel, and each member of the organization is at a certain level. Members are at different levels, and their responsibilities, work, and rights are different. The division of responsibilities of members is also clear. Centralize and unify leadership, make decision-making and communication channels easier and faster, and reduce the burden on managers. The organization structure is divided, the management is more professional, the affiliation relationship is clear, the powers and responsibilities are clear, and it helps to improve the efficiency of scientific research management.

\section{Loosely combined horizontal scientific research organization model}

Loose association is the unique nature of a university different from other organizations. It refers to the basic elements of a university organization, such as a college, a department, a department, a lecture, a research institute, or a research center, as well as professors and experts engaged in teaching and research in advanced learning. Scholars, in the operation of the organization, each maintains an independent, low-level working state or organization, so that the entire university is like a holding company with various knowledge groups[2].The reason is that knowledge differentiation is the main reason leading to the loose integration of university organizations, and it is the result of knowledge differentiation and tends to be highly specialized[3].Burton Clarke believes that the underlying structure of the higher education system is a discipline-based level that changes toward a differentiated and loose structure, and as the discipline and professional fields become more specialized, their form of aggregation becomes more and more loose, so it It follows the logic of disciplines, expertise, and specialized disordered states [4]. The basic structure of this type of organizational model is to set up a college according to the subject category or the first-level discipline. The members of the organization are completely independent according to their respective disciplines. They can choose the research direction according to their own interests and participate in the research group to jointly 
declare and complete the research projects. In essence, this is a structure of spontaneous organization, spontaneous regulation, and unified management. The academic atmosphere within the organization is relatively relaxed, and the duration of scientific research activities is long, which enhances the overall flexibility of the organization and helps the members of the organization to be relatively independent. Carry out scientific research and be suitable for basic research work.

\section{Interdisciplinary scientific research organization model of cross-cooperation}

Since the 1970s, the production and discovery of knowledge required the openness and integration of disciplines, and the cooperation between different disciplines has become a new trend of scientific research activities. It is obviously out of place to rely on a single discipline to solve complex problems, focusing on "problem research". The interdisciplinary research model has become a necessity. Chinese scholar Zhang et al., from an interdisciplinary perspective, combined with organizational structure theory, constructed a new university academic organization model based on interdisciplinary, as shown in Figure2[5]. Establish interdisciplinary scientific research organizations, organically link all disciplines of colleges and universities, and form a comprehensive academic system, from disorder to order, so as to ensure the efficient operation of scientific research organizations.

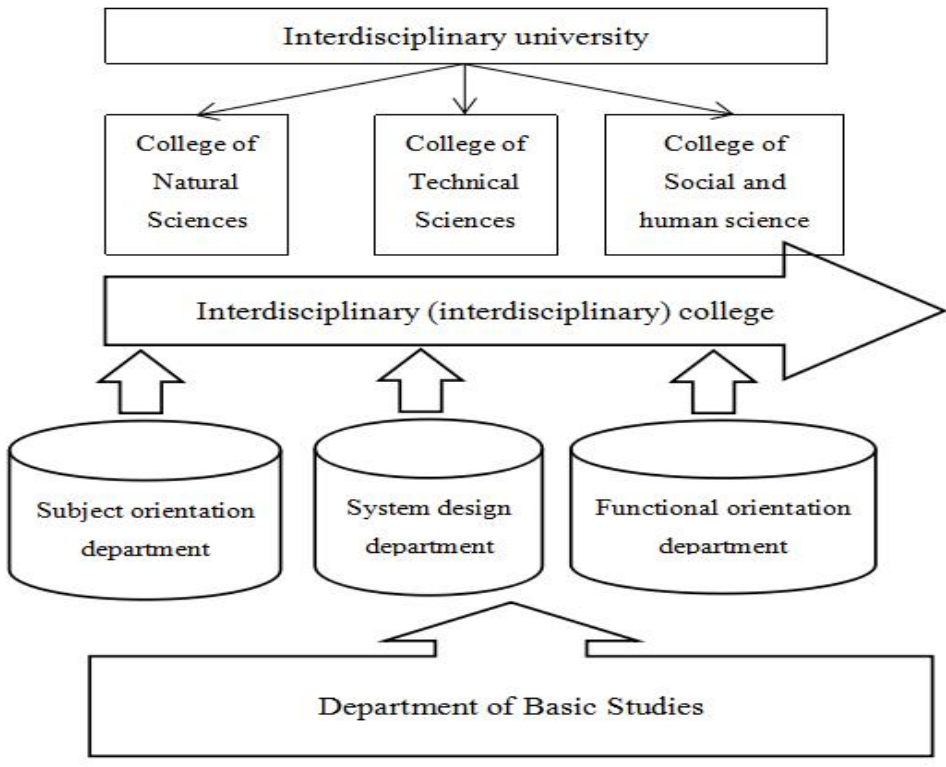

Figure 2. Interdisciplinary university mixed system structure academic organization model construction

\section{Strategies for Promoting the Development of Scientific Research Organization Models in Guangdong Universities}

Modern university research organization is a structure that integrates production, transmission and application knowledge. Each research organization is in a different environment. The resources and characteristics of the organization are different. Therefore, there is no possibility 
that there is a kind of "universal” suitable for all University research organization model.

\section{Establish talent pooling and advantage integration mechanism}

Talents are the scarcest resources for innovation and development, and universities should further play an important role in talent cultivation. First, adopt a flexible employment mechanism, hire high-level scientific and technological talents, and establish incentive policies and measures aimed at stimulating scientific researchers to actively participate in collaborative innovation, and establish specialized institutions or organizations independent of the personnel department to integrate universities, enterprises, and research institutes. The talent pool management of the Institute has formed a human resources integration operation mechanism of "people-oriented, talent mutual engagement; complementary disciplines, coordinated and coordinated"[6], and supports cross-disciplinary, interdisciplinary and inter-organizational experts to form research teams. Secondly, integrate academic figures in the existing subject areas, form an influential and attractive team of academic leaders, and lay the foundation for the gathering of high-level talents. Extensively select young academic backbones in various disciplines within and outside the school, unite them to participate in research work in research institutions, and strengthen the cultivation of academic expertise in academic backbones through internal and external training, visits, short-term training, and domestic and international academic conferences. We will strengthen our practical ability by taking measures such as post-employment training, and vigorously train young and middle-aged academic backbones. Finally, based on the development plan, combined with its own advantages, on the basis of fully understanding the basis of discipline research, the status of talents and the needs of economic and social development, we will concentrate our advantages, integrate resources, and form an advantageous integration mechanism. It is worth noting that the integration of university advantages is not simply to superimpose the advantages, but to continuously optimize the existing resources, maximize the people, finances and materials, realize the effective allocation of advantageous resources, and enhance the scientific research organization. Stability and vitality.

\section{Establish open sharing and survival of the fittest}

Organization is an integrated system composed of people, materials, machines and other resources under certain goals. Its growth and development are also affected by these components. For scientific research organizations, it is necessary to strengthen coordination and communication within the organization and with the outside world, integrate scientific and technological resources such as people, finances and materials, and improve their efficiency. First, break through the limitations of state-owned asset management, open up the use of scientific and technological resources inside and outside the school, effectively increase the degree of openness and utilization of science and technology resources within the school, establish a mechanism for sharing resources with other innovative entities, and achieve multi-party resource sharing. Secondly, organize an active academic atmosphere for various academic activities, encourage researchers to flow inside and outside the school, attract talents from relevant fields to join the research team, and strengthen the close integration between universities and other innovative subjects. Finally, establish a mechanism for survival of the fittest. Fully understand the needs of the members of the organization, especially to give substantial help to their career development, give them a variety of material and spiritual rewards, motivate them to obtain high-level topics, obtain high-quality scientific research results, and ensure that the research team has a permanent 
Not exhaustive scientific research strength. Introduce a competition mechanism within the scientific research organization, establish an assessment and reward and punishment system, strengthen the assessment management of scientific research personnel and research institutions, and give appropriate rewards to individuals with outstanding assessments, and support the excellent research teams or research institutions to adopt additional construction funds. Its construction and development. Individuals who fail to pass the continuous assessment may limit or cancel their qualifications for applying for scientific research projects and reduce investment in scientific research funds; for scientific research teams or research institutions that fail to pass the assessment, they may be rectified within a time limit, and if there is no effect after rectification, they may be merged. Or revoke.

\section{Establish a multi-investment and multi-party cooperation mechanism}

Technological innovation is an ongoing process that requires a large amount of research funding to ensure that scientific research continues. Colleges and universities should increase investment in scientific research, establish and improve mechanisms for diversified investment and multi-party cooperation. First of all, establish an independent system for the rational flow and allocation of people and property. On the basis of ensuring the necessary investment in the normal operation of the school, encourage research institutions to cooperate extensively with enterprises, civil organizations, and adopt a co-construction approach to attract more inflows of benign funds. And actively transform the research results into the market, improve the research ability of each innovation subject to attract more investment, and form a good cycle inside and outside the research organization. Second, establish and improve the research platform. Platform construction is an important support for collaborative innovation. It strengthens the coordination and communication between the research organization and the external environment, and gives full play to the role of the government as a government, university, scientific research institution and enterprise. Under the support of the innovation platform, universities and other innovative entities are deeply integrated to effectively stimulate the potential of scientific research organizations to innovate. Through joint research centers and research institutes, we will carry out extensive cooperation and joint research in various subject areas, give full play to their respective advantages, expand the scope of social services, and help regional and local governments solve important problems and key problems in economic construction. Local enterprises' technology transfer and transformation of results bring more economic and social benefits to local economic construction and social development.

\section{Acknowledgement}

This research was financially supported by the special fund project of disciplines and professional construction in higher education institutions in Guangdong Province. "Research on the innovation of scientific research organization model in the perspective of collaborative innovation--taking Guangdong Province as an example” (No.2013WYXM0169), Guangdong Higher Education Teaching Research and Reform Project " Research on the Reform of Teaching and Research Organizations in Applied Undergraduate Universities-Based on the Perspective of Innovative Talent Cultivation (No. 2018XJJXGG02), Guangdong Province Education Science "Twelfth Five-Year Plan" Project "Colleges of Higher Education, Economics and Research, "Five Rings Drive" Collaborative Education Research on Innovation Models and Mechanisms 
(No. 2013JK334), Education Research Project of Guangdong Education Research Institute "Study on Collaborative Innovation System Mechanism of Higher Education - Based on the Perspective of Institutional Innovation” (No. GDJY-2014-C-b015).

\section{References}

[1] Zhao-tong ZHOU, On Interdisciplinary Research Organizations and Management Innovation in Universities, J. Higher Agricultural Education. (2006)21-24.

[2] Ping-jun FAN, Ya-qing MAO, On the Knowledge Roots of Loose Combination of University Characteristics, J. Higher Education Research. (2006)51-54.

[3] Guang-cai YAN, University organizational characteristics and organizational culture model, China Education Management Review (Volume I), Educational Research Press, Bei Jing, 2003.

[4] Burton Clark, Higher Education System--International Study of Academic Organizations, Hangzhou University Press, Hang Zhou, 1994.

[5] Wei ZHANG, Xiao-dong ZOU, Jin CHEN, The construction of a new type of university academic organization model based on interdisciplinary research, J. Scientific research. (2002)362-366.

[6] Hong-quan XIE, Xiao-bo ZHOU, Da-hai GAO, The Role and Function of Colleges and Universities in Promoting Collaborative Innovation-Based on the Thinking of Southwest University of Science and Technology, J. Higher Education Research, (2014)43-46. 